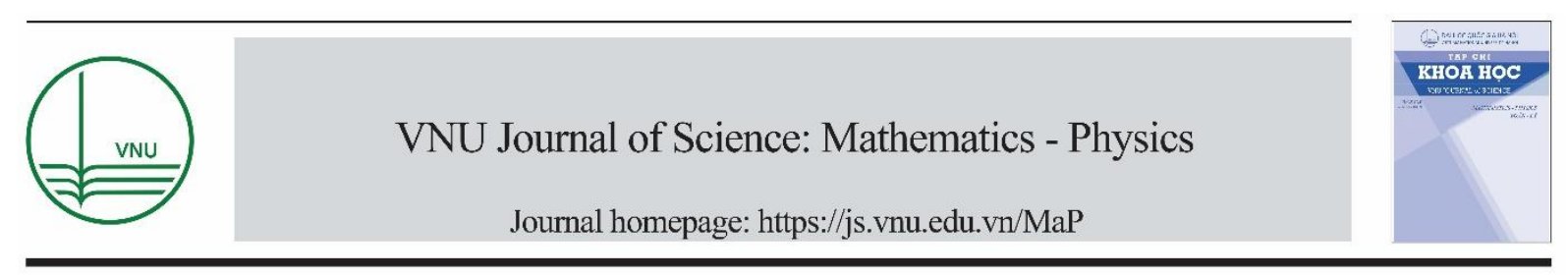

\title{
Effect of Substituted Concentration on Structure and Magnetic Properties of $\mathrm{Y}_{3} \mathrm{Fe}_{5-\mathrm{x}} \mathrm{In}_{\mathrm{x}} \mathrm{O}_{12}$
}

\author{
Vu Thi Hoai Huong, Dao Thi Thuy Nguyet, Nguyen Phuc Duong* \\ ITIMS, Hanoi University of Science and Technology, \\ No. 1, Dai Co Viet, Hai Ba Trung, Hanoi, Vietnam
}

Received 09 November 2018

Revised 18 December 2018; Accepted 18 December 2018

\begin{abstract}
This study examines the effect of substituted concentration on the structure and magnetic properties of $\mathrm{Y}_{3} \mathrm{Fe}_{5-\mathrm{x}} \mathrm{In}_{\mathrm{x}} \mathrm{O}_{12}(x=0.1 \div 0.7)$ powder samples prepared using the sol-gel method. The morphological properties of the samples were analysed using XRD, SEM. The single phase of garnet was obtained in $x=0.1 \div 0.6$ samples. The lattice parameters of the samples exhibit a linear increase with the increasing $\mathrm{In}^{3+}$ content, which can be explained by a substitution of $\mathrm{In}^{3+}$ ions for $\mathrm{Fe}^{3+}$ ions, considering the larger ionic radius of $\operatorname{In}^{3+}$ compared with that of $\mathrm{Fe}^{3+}$. Crystallite sizes were determined via the XRD data which are of $38-49 \mathrm{~nm}$ while the particle sizes were estimated from SEM images to be in range of $50-100 \mathrm{~nm}$. Magnetization and Curie temperature of the single phase samples were studied by magnetization curves in fields up to $10 \mathrm{kOe}$ and in the temperature range from $80 \mathrm{~K}$ to $560 \mathrm{~K}$. With the increase of $\mathrm{In}^{3+}$, the magnetization gradually increases while the Curie temperature decreases due to the occupation of In atoms at the $a$ sites and the reduction of intersublattice interaction, respectively.
\end{abstract}

Keywords: Yttrium iron garnet, Indium substitution, cation distribution, magnetization, Curie temperature.

\section{Introduction}

Yttrium ferrite garnet $\mathrm{Y}_{3} \mathrm{Fe}_{5} \mathrm{O}_{12}(\mathrm{YIG})$ is known as one of the most important garnets for microwave applications. It is material that widely used in microwave devices, transformers, electric generators, bioprocessing, and storage devices [1-7] because of its combine good high-frequency dielectric properties with a ferrimagnetic order. YIG has three different crystallographic sites with $16 \mathrm{Fe}^{3+}$ ions in the octahedral $[a]$ site, $24 \mathrm{Fe}^{3+}$ ions in the tetrahedral site $(d)$ and $24 \mathrm{Y}^{3+}$ ions in the dodecahedral $\{c\}$ site. The $\mathrm{Fe}$ atoms on the octahedral sites couple anti-ferromagnetically to the $\mathrm{Fe}$ atoms on the tetrahedral

\footnotetext{
*Corresponding author. Tel.: 84-915527063.

Email: duong@itims.edu.vn

https//doi.org/ 10.25073/2588-1124/vnumap.4298
} 
sites $\left(J_{\text {ad }}<0\right)$ and there is no coupling to the dodecahedral sites because yttrium is a nonmagnetic atom. The magnetization of YIG per formula unit calculated by 3 tetrahedral and 2 octahedral sites, corresponding to a net moment of $5 \times(3-2) \mu_{\mathrm{B}}=5 \mu_{\mathrm{B}}$. The interest in the structural, microstructural and magnetic properties of YIG has been due to the fact that all these properties can be widely varied by dopant substitutions [8-10]. In previous studies, nonmagnetic ion as $\mathrm{V}^{5+}$ was substituted on Fe ions at $d$ site and that is reason leading to reduce magnetization and Curie temperature of the system $[11,12]$. In most applications of ferrite garnets, enhancement of the magnetization of the materials is required which can be achieved by substituting non-magnetic ions on the $a$ sublattice. In this work, $\mathrm{In}^{3+}$ ions were substituted for $\mathrm{Fe}^{3+}$ and the effect of the presence of non-magnetic ions on the structure and magnetic properties were investigated.

\section{Experimental}

\subsection{Sample preparation}

The $\mathrm{Y}_{3} \mathrm{Fe}_{5-\mathrm{x}} \mathrm{In}_{\mathrm{x}} \mathrm{O}_{12}$ nanoparticle samples $(x=0 \div 0.7)$ were prepared by using sol-gel method. Starting materials for preparation of the samples were high purity $\mathrm{Fe}\left(\mathrm{NO}_{3}\right)_{3}, \mathrm{Y}_{2} \mathrm{O}_{3}, \mathrm{In}_{2} \mathrm{O}_{3}(99,99 \%$, Sigma Aldrich). The oxides were dissolved in $\mathrm{HNO}_{3} 1 \mathrm{M}$ to form nitrate solutions. The metal nitrate solutions were mixed the required amount of the metal ions in a stoichiometric ratio of $\mathrm{Y}: \mathrm{Fe}: \mathrm{In}=3:(5-x): x$. An aqueous solution of citric acid was added into the solution with the total cation/citric acid molar ratio is $1 / 3$. The mixtures were stirred at $400 \mathrm{rpm}$ and slowly evaporated at $80^{\circ} \mathrm{C}$ to form gels. The gels were dried at $95^{\circ} \mathrm{C}$ for more than 12 hours in order to form xero-gels. The nanoparticle samples were obtained after burning the xero-gels at $400^{\circ} \mathrm{C}$ in 2 hours and annealing at $900^{\circ} \mathrm{C}$ in 5 hours.

\subsection{Analytical methods}

The phase structure and crystallite sizes of the powder samples at room temperature were investigated using $\mathrm{X}$-ray diffraction (XRD) $(\mathrm{Cu}-\mathrm{K} \alpha$, Siemens D-5000) operating with $\mathrm{Cu}-\mathrm{K} \alpha$ radiation $(\lambda=1.54060 \AA)$ in the range of $20^{\circ}-70^{\circ}$ by a $2 \theta$ scan mode and $0.03^{\circ}$ scan step at room temperature. The grain size and morphology of samples were measured by using Scanning Electron Microscope (SU3500). Magnetic measurements were carried out by using a vibrating sample magnetometer (VSM) in maximum applied magnetic field of $10 \mathrm{kOe}$ and at temperatures from 88 to $550 \mathrm{~K}$. For the magnetic measurements, the nanoparticles were pressed in the forms of platelets.

\section{Results and discussion}

\subsection{Structure, cation distribution and morphology of particle samples}

Fig. 1 shows the XRD patterns of the $\mathrm{Y}_{3} \mathrm{Fe}_{5-\mathrm{x}} \mathrm{In}_{\mathrm{x}} \mathrm{O}_{12}(x=0-0.7)$ nanoparticle samples sintered at $900^{\circ} \mathrm{C}$ in 8 hours in which, the planes of a cubic unit cell of garnet structure were indexed as (321), (400), (420), (422), (521), (611), (444), (640), (642), (800), (752), (840). On the others XRD studies of samples sintered at $800^{\circ} \mathrm{C}$ and $850^{\circ} \mathrm{C}$ in 8 hours, the amount of $\mathrm{YFeO}_{3}$ phase is present. Therefore, the temperature of $900^{\circ} \mathrm{C}$ in 8 hours is the lowest temperature of the sol-gel method for preparing In substituted YIG nanoparticle samples. This temperature is also lower than the $1000^{\circ} \mathrm{C}$ of the mechanical alloying method [13] and conventional mix oxide route [14]. 

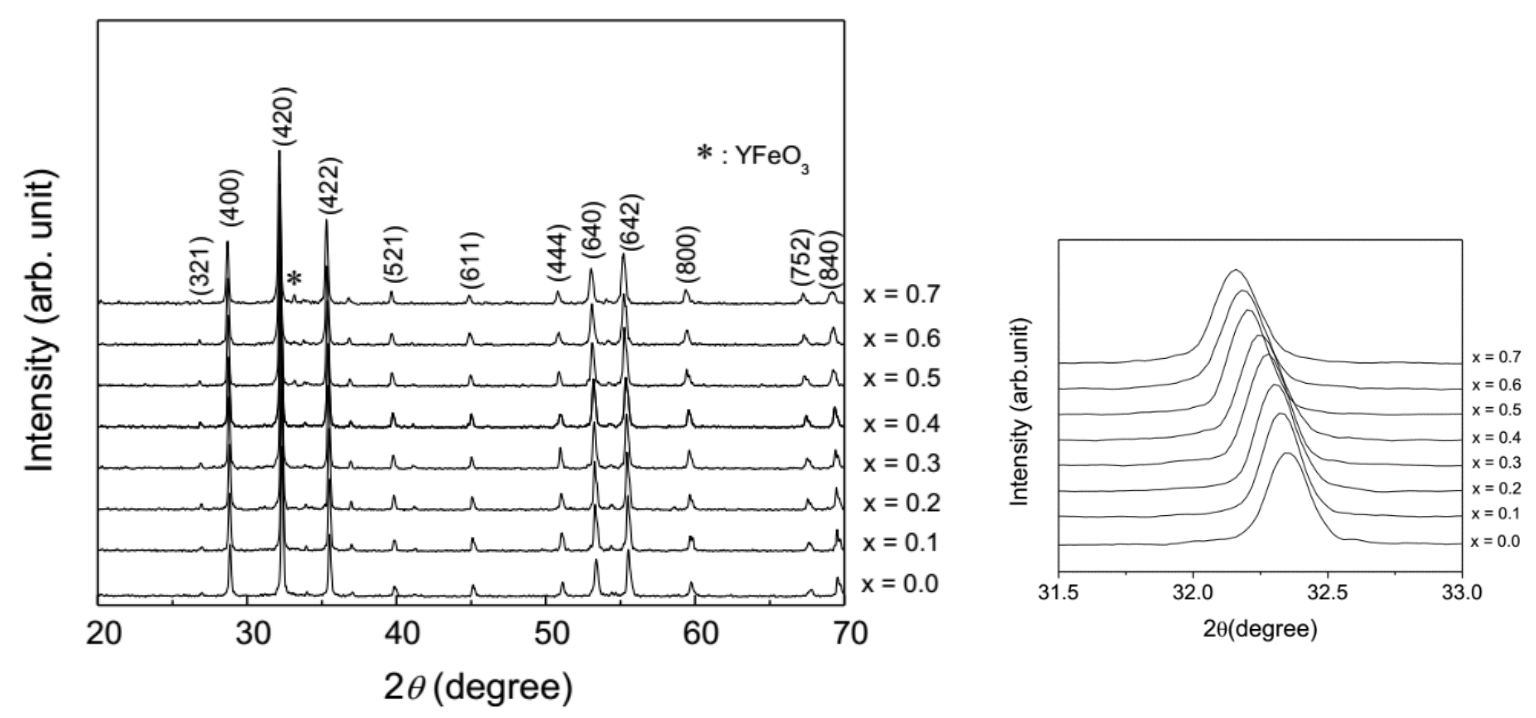

Figure 1. XRD patterns of $\mathrm{Y}_{3} \mathrm{Fe}_{5-x} \mathrm{In}_{x} \mathrm{O}_{12}(x=0-0.7)$ samples. Small figure is enlarged image of diffraction peak (420).

The samples with the In concentrations, $x \leq 0.6$ are of single phase while the sample $x=0.7$ exhibited the second phase orthoferrite $\mathrm{YFeO}_{3}$. Similar result is also observed in other study on indium substituted YIG polycrystalline samples [15]. The lattice constant, $a$, was computed using the interplanar spacing $d$ and the corresponding Miller indices $(h, k, l)$. It is also observed that $a$ increases from12.38 $\AA$ to 12.442 $\AA$ as $x$ increasing from 0.1 to 0.7 . Fig. 2 shows monotonous increasing of lattice constants with increasing of $\mathrm{In}^{3+}$ contents. The observed variation in lattice constant can be explained by Vegard's law, according to that, if the radius of displacing ion is larger than the displaced ion, the lattice is expanded and the lattice constant increases [16]. The ionic radius of $\operatorname{In}^{3+}(0.79 \AA-$ in octahedral site $)$ is larger than that of $\mathrm{Fe}^{3+}(0.645 \AA$ - in octahedral site; $0.49 \AA$ - in tetrahedral site), resulting in the gradual increase of the lattice constant with increasing $\mathrm{In}^{3+}$ content. The diffraction peaks (420) of the substituted samples are found to shift to lower Bragg angles in comparison with the pure sample $(x=0)$ as shown in the small Fig. 1. The value of $a$ obtained at $x=0.1 \div 0.4$ samples in this study are similar to the polycrystalline samples with the same concentration prepared by conventional mixed oxide [14] and mechanical alloying [13].

Table 1. Lattice parameter $a(\AA)$ and average crystallize size $D_{\mathrm{XRD}}(\mathrm{nm})$ of $\mathrm{Y}_{3} \mathrm{Fe}_{5-x} \mathrm{In}_{x} \mathrm{O}_{12}(x=0 \div 0.7)$

\begin{tabular}{lllllllll}
\hline & $x=0$ & $x=0.1$ & $x=0.2$ & $x=0.3$ & $x=0.4$ & $x=0.5$ & $x=0.6$ & $x=0.7$ \\
\hline$a(\AA)$ & 12.371 & 12.38 & 12.387 & 12.398 & 12.407 & 12.423 & 12.433 & 12.442 \\
$D_{\text {XRD }}(\mathrm{nm})$ & 38 & 49 & 47 & 46 & 43 & 41 & 43 & 42
\end{tabular}

The average crystal size $D_{\text {XRD }}$ determined based on the width of the (420) peak using the Debye Scherrer varies from 41 to $49 \mathrm{~nm}$ as shown in Table 1. On the other hand, the morphological shape particle of samples were characterized by SEM images shown that average sizes are in the range of 50 $-100 \mathrm{~nm}$. SEM image of $\mathrm{Y}_{3} \mathrm{Fe}_{5-x} \mathrm{In}_{x} \mathrm{O}_{12}(x=0.2 ; 0.3 ; 0.4 ; 0.6)$ samples were indicated in Fig. 3 , in which, due to the influence of temperature during annealing process, the grains are melted and clustered 
together, forming a porous structure. The difference in average crystal size and particle size is explained by the fact that each particle observed on the SEM image contains several crystallites which have dimensions in the orders of $D_{\text {XRD }}$ values. The structural heterogeneity region between these grains is also known as crystal dislocation region where the crystal growth temporarily halted [17].

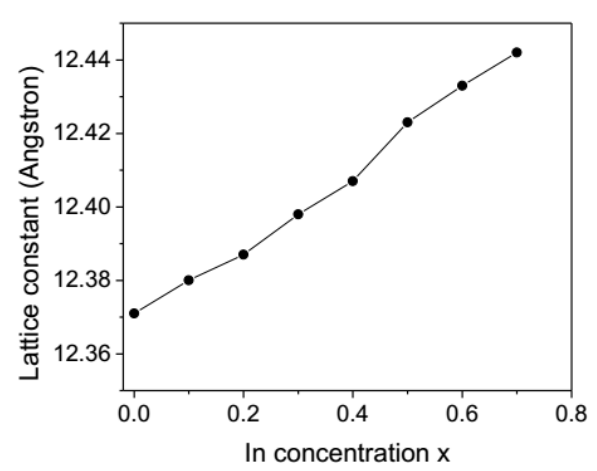

Figure 2. Lattice constant of $\mathrm{Y}_{3} \mathrm{Fe}_{5-\mathrm{x}} \mathrm{In}_{\mathrm{x}} \mathrm{O}_{12}$ $(\mathrm{x}=0 \div 0.7)$ samples.

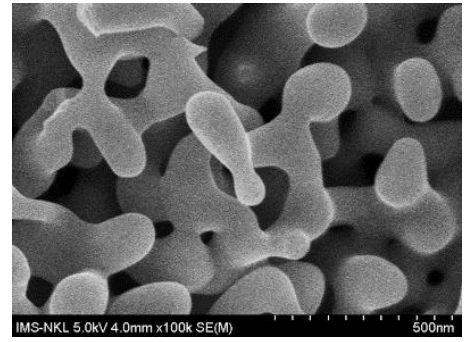

$\mathrm{x}=0.2$

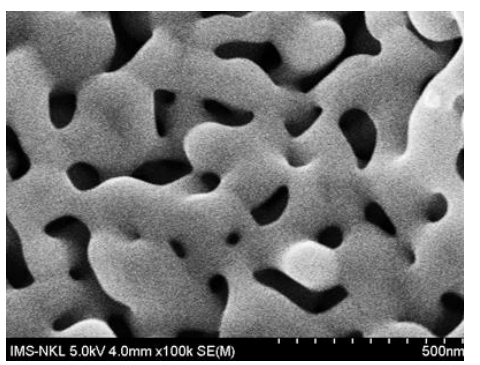

$\mathrm{x}=0.4$

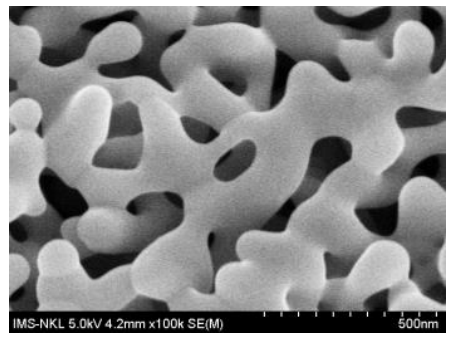

$\mathrm{x}=0.3$

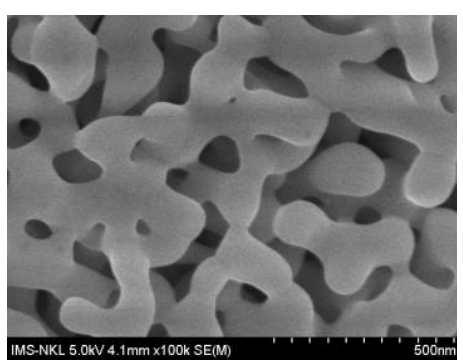

$x=0.6$

Figure 3. SEM micrographs of $\mathrm{Y}_{3} \mathrm{Fe}_{5-\mathrm{x}} \mathrm{In}_{\mathrm{x}} \mathrm{O}_{12}$ $(\mathrm{x}=0.2 ; 0.3 ; 0.4 ; 0.6)$.

\subsection{Magnetic properties}

Magnetic properties of samples were studied by means of origin magnetization curves measured in magnetic fields up to $10 \mathrm{kOe}$ at temperature from $88 \mathrm{~K}$ to $570 \mathrm{~K}$. Fig. 4 demonstrates the $M(H)$ curves of $\mathrm{Y}_{3} \mathrm{Fe}_{5-x} \mathrm{In}_{x} \mathrm{O}_{12}(x=0.1 \div 0.6)$ samples at $88 \mathrm{~K}$. At all of the survey temperatures, the $M(H)$ curves reach saturation state in a magnetic field greater than $2 \mathrm{kOe}$. The value of the saturation magnetization $M_{\mathrm{s}}$ were determined based on the flat part of the curves in the higher field region. $M_{\mathrm{s}}(T)$ curves in Fig. 5 show the dependence of $M_{\mathrm{s}}$ value of samples on the temperature. The saturation magnetization $M_{\mathrm{s}}(0)$ at $0 \mathrm{~K}$ were determined by extrapolation of the graphical plot of $M_{\mathrm{s}}$ against $T$ to $T=0$ according to a modified Bloch law [18]: $M_{\mathrm{s}}(T)=M_{\mathrm{s}}(0)\left(1-B T^{\star}\right)$ where $B$ is the Bloch's constant and $\alpha$ is the Bloch exponent The experimental curves were the best reproduced with $\alpha \approx 1.6$ as shown in Fig. 5. The extrapolated magnetic moments in ground state express in Bohr magneton per formula unit $\left(\mu_{\mathrm{B}} / \mathrm{f} . \mathrm{u}\right)$ were calculated according to the formula: $m(0)=M_{\mathrm{s}}(0) \times W / 5585$ where $W$ is the molar mass.

In order to evaluate the effect of substituted concentrations on the magnetic moment of samples, the experimental magnetization values are identified at $0 \mathrm{~K}$ and compared with theory values. Applying the Néel model for the assumption that In ions substituted in $a$ sublattice, the theoretical values of $m(0)^{\text {theo }}$ of substituted samples are identified based on formula (4): $m(0)^{\text {theo }}=m^{\text {(tetra) }}-m^{\text {(octa) }}=3 \times 5 \mu_{\mathrm{B}}-(2-x) \times 5$ 
$\mu_{\mathrm{B}}$ where $m^{\text {(tetra) }}$ and $m^{\text {(octa) }}$ are magnetization of tetrahedral and octahedral sites at $0 \mathrm{~K}$. The theory and experimental values $m(0)^{\exp }$ of magnetizations are listed in Table 2.

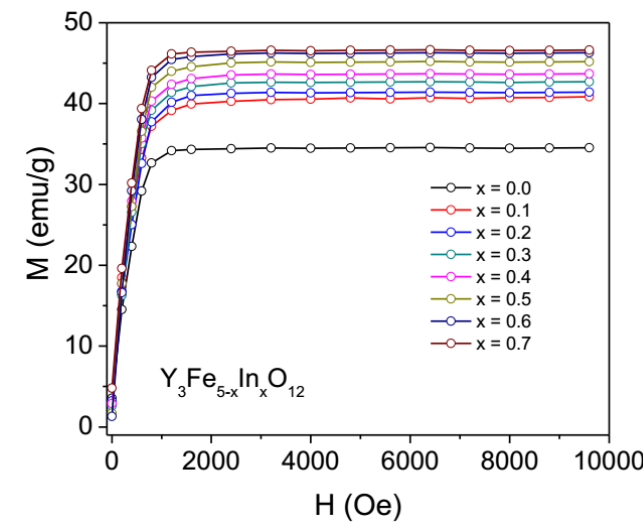

Figure 4. The $M(H)$ curves of $\mathrm{Y}_{3} \mathrm{Fe}_{5-\mathrm{x}} \mathrm{In}_{\mathrm{x}} \mathrm{O}_{12}$ $(x=0.1 \div 0.7)$ samples at $88 \mathrm{~K}$.

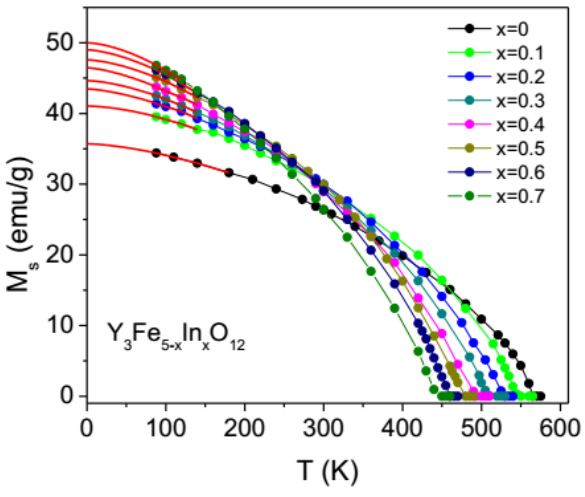

Figure 5. Temperature dependence of magnetization values $M_{\mathrm{s}}$ of $\mathrm{Y}_{3} \mathrm{Fe}_{5-\mathrm{x}} \mathrm{In}_{\mathrm{x}} \mathrm{O}_{12}$ $(\mathrm{x}=0 \div 0.7)$ samples.

The increase of magnetic moment with increasing indium contents indicates that In atoms prefer to enter the $a$ site. The experiment values are smaller than the theoretical values for all the samples which can be explained due to both dislocations and canting of the magnetic moments in the main phase. The canting effect was reported previously for Sc substituted YIG samples in which non-magnetic Sc atoms occupy the a site [18].

The Curie temperature $T_{\mathrm{C}}$ values of $\mathrm{Y}_{3} \mathrm{Fe}_{5-x} \mathrm{In}_{x} \mathrm{O}_{12}$ samples are listed in Table 2. The $T_{\mathrm{C}}$ of YIG sample is similar to that of the bulk counterpart [19] while the $T_{\mathrm{C}}$ of substituted samples decreases gradually with $x$. The reduction of $T_{\mathrm{C}}$ is due to the magnetic dilution effects. Comparison is made among the $T_{\mathrm{C}}$ values of magnetically diluted YIG systems which is shown in Table 2. It is seen that with the same substitution level, $T_{\mathrm{C}}$ decreases faster in the systems with substitution takes place at the $d$ sites compared to that at the $a$ sites. This phenomenon can be explained by the fact that the number of pair interactions between Fe ions in the $a$ and $d$ sublattice for the case (3-x) $\times 2$ is larger than that for the case $3 \times(2-x)$ where $x$ represents the mole fraction of non-magnetic ions.

Table 2. Saturation magnetization $M_{\mathrm{s}}(0)$ and Curie temperature $T_{\mathrm{C}}$ of $\mathrm{Y}_{3} \mathrm{Fe}_{5-x} \mathrm{In}_{x} \mathrm{O}_{12}(x=0 \div 0.7)$ samples

\begin{tabular}{|c|c|c|c|c|c|c|c|c|}
\hline$x$ & 0 & 0.1 & 0.2 & 0.3 & 0.4 & 0.5 & 0.6 & 0.7 \\
\hline$M^{\exp }(0 \mathrm{~K})(\mathrm{emu} / \mathrm{g})$ & 35.5 & 41.05 & 43.58 & 44.5 & 46.56 & 47.58 & 49 & 50 \\
\hline$m\left(\mu_{\mathrm{B}} / \text { f.u. }\right)^{\exp }(0 \mathrm{~K})$ & 4.72 & 5.47 & 5.84 & 6.04 & 6.34 & 6.54 & 6.78 & 6.98 \\
\hline$m\left(\mu_{\mathrm{B}} / \mathrm{f} . \mathrm{u} .\right)^{\text {theo }}(0 \mathrm{~K})$ & 5.0 & 5.5 & 6.0 & 6.5 & 7.0 & 7.5 & 8.0 & 8.5 \\
\hline$T_{\mathrm{C}}(\mathrm{K})$ & 560 & 546 & 530 & 512 & 493 & 478 & 460 & 405 \\
\hline$T_{\mathrm{C}}(\mathrm{K})\{\mathrm{Y}\}_{3}\left[\mathrm{Fe}_{2}\right]\left(\mathrm{Fe}_{3-\mathrm{x}} \mathrm{Al}_{x}\right) \mathrm{O}_{12}[20]$ & - & - & - & - & - & 480 & - & - \\
\hline $\begin{array}{l}T_{\mathrm{C}}(\mathrm{K}) \\
\left\{\mathrm{Y}_{3-\mathrm{x}} \mathrm{Ca}_{\mathrm{x}}\right\}\left[\mathrm{Fe}_{2-\mathrm{x}} \mathrm{Sn}_{\mathrm{x}}\right]\left(\mathrm{Fe}_{3}\right) \mathrm{O}_{12}[21]\end{array}$ & - & 530 & - & 502 & - & 463 & - & - \\
\hline
\end{tabular}




\section{Conclusion}

In summary, the present study has shown that $\mathrm{Y}_{3} \mathrm{Fe}_{5-x} \mathrm{In}_{x} \mathrm{O}_{12}(x=0 \div 0.7)$ powders with size between $50-100 \mathrm{~nm}$ were fabricated using the sol-gel method. The single phase structural was observed for $x$ as large as 0.6. At $x=0.7$, a small amount of orthoferrite $\mathrm{YFeO}_{3}$ appears $(\sim 2 \%)$. The value of lattice constant increases with increasing $x$. Our results show that $\mathrm{In}^{3+}$ ions can replace for Fe with the concentration up to $x=0.7$. Saturation magnetization of substituting samples increases with increasing of $\operatorname{In}^{3+}$ concentration $x$ while the Curie temperature gradually decreases. The magnetic properties can be understood with assumption that In atoms mainly occupy the octahedral sites.

\section{Acknowledgments}

This work was financially supported by the Vietnam National Foundation for Science and Technology Development under Grant No. 103.02-2016.05.

\section{References}

[1] R. L. Streever, Anisotropic exchange in ErIG, Journal of Magnetism and Magnetic Materials 278 (1-2) (2014) 223230.

[2] N.I. Tsidaeva, The magnetic and magnetooptical properties of Y-substituted erbium iron garnet single crystals, Journal of Alloys and Compounds 374 (1-2) (2004) 160-164.

[3] Y.Nakata, T. Okada, M. Maeda, S. Higuchi and K. Ueda, Effect of oxidation dynamics on the film characteristics of Ce:YIG thin films deposited by pulsed laser deposition, Optics and Lasers in Engineering 44 (2) 2006, 147-154.

[4] M. Laulajainen, P. Paturi, J. Raittila, H. Huhtinen, A.B. Abrahamsen, N.H. Andersen and R. Laiho, $\mathrm{Bi}_{\mathrm{x}} \mathrm{Y}_{3-\mathrm{x}} \mathrm{Fe}_{5} \mathrm{O}_{12}$ thin film prepared by laser ablation for magneto-optical imaging of superconducting thin films, Journal of Magnetism and Magnetic Materials 279 (2-3) (2004) 218-223.

[5] A.A. Lagutin, G.E. Fedorov, J. Vanacken and D. Herlach, Magnetic properties of dysprosium Yttrium ferrite garnet in pulsed magnetic fields at low temperatures, Journal of Magnetism and Mmagnetic Materials 195 (1999) 97-106.

[6] S.A. Nikotov, Nonlinearity: Magneto-optic microwave interactions. Towards new devices, Journal of Magnetism and Magnetic Materials (196-197) (1999) 400-403.

[7] C.S. Tsai, Wideband tunable microwave devices using, European Ceramic Society 23 (14) (2003) 2721-2726.

[8] A. Sztaniszlav, M. Farkas-Jahnke, M. Balla, Kinetics of garnet formation in $\mathrm{In}^{3+}$ substituted systems, Journal of Magnetism and Magnetic Materials 215-216 (2000) 188-193.

[9] R.G. Vidhate, V.D. Murumkas, R.G. Dorik, N.M. Makne, S.R. Nimbore, K.M. Jadhav, Magnetic properties of In Substituted ytrium iron garnet (YIG), Rev. Res. 1(10) (2012) 1-4.

[10] G. Cuijing, Z. Wei, J. Rongjin, Z. Yanwei, Effect of $\operatorname{In}^{3+}$ substitution on the structure and magnetic properties of multi-doped YIG ferrites with low saturation magnetizations, Journal of Magnetism and Magnetic Materials 323, (2011) 611-615.

[11] Vu Thi Hoai Huong, Dao Thi Thuy Nguyet, To Thanh Loan, Luong Ngoc Anh, Nguyen Phuc Duong, Than Duc Hien, Structural and magnetic properties of $\mathrm{Y}_{3-2 x} \mathrm{Ca}_{2 x} \mathrm{Fe}_{5-x} \mathrm{~V}_{x} \mathrm{O}_{12}$ nanoparticles prepared by sol-gel method, Proceeding of the $3^{\text {rd }}$ International Conference on Advanced Materials and Nanotechnology (2016) 219-223.

[12] Imaddin A. Al-Omari, Ralph Skomski, David J. Sellmyer, Magnetic properties of $\mathrm{Y}_{3-2 x} \mathrm{Ca}_{2 x} \mathrm{Fe}_{5-x} \mathrm{~V}_{x} \mathrm{O}_{12}$ garnets, Advances in Materials Physics and Chemistry 2 (2012) 116-120.

[13] Rodziah Nazlan, Mansorhashim, Idza Riati Ibrahim, Fadzidah Mohd Idris, Wan Norailiana Wan Ab Rahman, Nor Hapishah Abdullah, Ismayadi Ismail, Saikannu Kanagesan, Zulkifly Abbas, Rabaah Syahidah Azis, Influence of Indium substitution and microstructure changes on the magnetic properties evolution of $\mathrm{Y}_{3} \mathrm{Fe}_{5-x} \mathrm{In}_{x} \mathrm{O}_{12}(x=0.0-$ 0.4), Journal of Material Science: Materials in Electronics 26, 6 (2015) 3596-3609. 
[14] M. Niyaifar, A. Beitollahi, N. Shiri, M. Mozaffari, J. Amighian, Effect of indium addition on the structure and magnetic properties of YIG, Journal of Magnetism and Magnetic Materials 322 (2010) 777 - 779.

[15] J. Richard Cunningham Jr and Elmer E. Anderson, Effect of indium substitution in Yttrium iron garnet. High permeability garnets, Journal of Applied Physics 32, (1961) S388.

[16] L. Vegard Dr. Phil, LV. Results of crystal analysis. -III, Philosophical magazine Series 6, 32: 191, 505 - 518.

[17] Ronald W. Armstrong, Crystal dislocations, Crystals 6, 1 (2016) 9.

[18] Gerald F. Dionne, Molecular field coefficients of substituted yttrium iron garnets, Journal of Applied Physics. 41 (1970) 4874.

[19] M.A. Gilleo, Ferromagnetic insulators: Garnets, in: E.P. Wohlfarth (Ed.), Handbook of Magnetic Materials, Volume 2, North-Holland Publishing Company, 1980, 1-54.

[20] Z. Azadi Motlagh, M. Mozaffari, J. Smighian, Preparation of nano-sized Al-substituted yttrium iron garnets by the mechanochemical method and investigation of their magnetic properties, Journal of Magnetism and Magnetic Materials 321 (2009) 1980-1984.

[21] P. Belov and I.S. Lyubutin, Effective magnetic fields at tin nuclei in substituted iron garnets $\mathrm{Ca}_{\mathrm{x}} \mathrm{Y}_{3-\mathrm{x}} \mathrm{Sn}_{\mathrm{x}} \mathrm{Fe}_{5-\mathrm{x}} \mathrm{O}_{12}$, Soviet Physics JETP 22 (3) (1966) 518 - 520. 